\title{
Learning to Read and Spell English Words by Chinese Students
}

\author{
Che Kan Leong \\ Department of Educational Psychology \& Special Education \\ University of Saskatchewan, Canada \\ and Department of Educational Psychology \\ The Chinese University of Hong Kong \\ Li Hai Tan \\ Joint Laboratories for Language \& Cognitive Neuroscience \\ Department of Linguistics \\ The University of Hong Kong
}

Pui Wan Cheng and Kit Tai Hau

Department of Educational Psychology

The Chinese University of Hong Kong

This study examined the structural relationships between (a) the latent independent constructs of orthographic and lexical knowledge and phonological sensitivity and (b) the effect of these constructs on the latent construct of literacy manifested by reading aloud and spelling regular and exception English words in 156 Cantonese-speaking Chinese students ( $M$ age $=10.8$ years) who were learning English as a second language in Hong Kong. Three carefully designed and item-analyzed indicators subserved the construct of orthographic and lexical knowledge, and another three indicators subserved the construct of phonological sensitivity. Our hypothesis of greater contribution of word-specific orthographic and lexical knowledge than phonological sensitivity to learning to read and spell English words in these Chinese children was supported by results from multiple regression, principal component analyses and especially by structural equation modeling. The various goodness-of-fit

Requests for reprints should be sent to Che Kan Leong, Department of Educational Psychology \& Special Education, University of Saskatchewan, 28 Campus Drive, Saskatoon, SK, Canada S7N 0XI. E-mail: leong@sask.usask.ca 
indexes showed the appropriateness of the indicators in measuring the latent constructs as well as the relationships among these constructs.

There is now strong evidence that for alphabetic language systems, children's phonological sensitivity to the speech sound structure of spoken words is important in learning to read (Adams, 1990; Byrne, 1996; Goswami \& Bryant, 1990; Wagner \& Torgesen, 1987; Wagner et al., 1997). Specifically, the components of phonological sensitivity, phonological memory, and phonological access to lexical items have been shown to be predictive of reading acquisition (Wagner \& Torgesen, 1987).

Similar to reading, spelling requires knowledge of the alphabetic system in terms of letter names, functional units of letters or letter clusters, blending of phonemes, segmenting of words into phonemes, and synthesizing phonemes into graphemes. Although phonological sensitivity is important for spelling, spellers should also know which grapheme represents which speech sound or sounds and the positions in which the letters or letter clusters occur. This orthographic knowledge also applies to reading as shown by Treiman and her colleagues (Cassar \& Treiman, 1997; Treiman, 1993; Treiman \& Cassa, 1997). For example, children in the second half of the first grade appreciate the orthographic restriction against the initial consonant cluster $c k$ as in * ckan but accept the digraph for the final and medial positions as in the words sick or package. Treiman suggested that children begin learning about the orthographic, phonological, and morphological characteristics of spelling almost from their first contacts with print.

Acquiring knowledge of the alphabetic language system is thus central to the intertwined reading and spelling process. Reading words and spelling words are "almost" one and the same process, as discussed by Ehri (1997) from both her theoretical and empirical studies. In her analysis, she showed that reading and spelling familiar words both draw on access to lexical memory of analogous spelling patterns (for reading) and analogous pronunciations (for spelling) and that reading and spelling unfamiliar words utilize knowledge of letter patterns and morphographs, sensitivity to speech sounds, and sensitivity to grapheme-phoneme units (for reading) and phoneme-grapheme units (for spelling).

\section{THIS STUDY}

In this study, we investigated components of English word reading and spelling in a sample of 156 Cantonese-speaking Chinese children age 10 to 12 in Hong Kong. Although there is some evidence that similar component processes are involved in reading acquisition from linguistically very diverse second-language (L2) learners as compared with native speaking English children (e.g., Chiappe, Siegel, \& 
Wade-Woolley, 2002; Lesaux \& Siegel, 2003), we asked specifically if the underlying orthographic, lexical, and phonological processes contribute to English word reading and spelling in Chinese children in similar ways. If so, what is the relative contribution of these underlying or latent independent constructs of orthographic and lexical knowledge and phonological sensitivity to the underlying or latent dependent construct of "literacy"? To answer these research questions we designed or adapted appropriate orthographic, lexical, and phonological-processing tasks in our study and used multiple regression, principal component analyses, and structural equation analyses to converge on an estimate of the "causal" links between and among these latent constructs.

There are several recent studies that motivated our exploration of some underlying constructs in Chinese children learning to read and spell English words. One line of research is from studies of the possible transfer of cognitive-linguistic processes from analytic reading of Chinese characters to the analysis and synthesis of lexical and sublexical units of English to enhance L2 reading (Geve \& Wang, 2001). The general finding is that any such transfer to phonological sensitivity is specific and not general, and much depends on the phonological similarity of the first language (L1) to the ambient English language. For example, Muljani, Koda, and Moates (1998) found an orthographic similarity effect in lexical decision in that the closer the intraword structure in L1 (Indonesian and Chinese in the study) the closer is the facilitating effect in building up an interletter network in the ambient L2 English. Koda (2000) also found evidence that L1 processing experience in the morphosyllabic Chinese and the morphologically sensitive alphabetic Korean influences certain aspects of L2 (English) morphological awareness in adult second-language learners and that both $\mathrm{L} 1$ and $\mathrm{L} 2$ processing experience promotes the development of L2 lexical learning. Further, Wang, Koda, and Perfetti (2003) showed that Chinese college learners of English relied more on orthographic than phonological information and made more incorrect phonological errors, as compared with Korean college students with similar literacy background, in a semantic category judgment task (e.g., whether rows is "a flower"). In a second experiment, these researchers gave their Chinese and Korean participants a phoneme deletion task with phonemes existing in both Chinese and Korean and asked them to delete the designated speech sound, say aloud the new word, and write down this new word, which should show a different spelling from the original item (e.g., new word of my from might after deleting the $/ \mathrm{t} /$ sound). The Chinese participants were found to produce more phonological but orthographically plausible written responses, and the Korean participants were significantly better than their Chinese counterparts in deleting the designated phonemes orally.

In their study of phoneme manipulation tasks in Chinese-English and Spanish-English bilingual children between kindergarten and second grade, Bialystok, Majumder, and Martin (2003) did not find a general bilingual advantage for English word identification and obtained group differences only for phoneme segmen- 
tation in their Spanish-English bilinguals. Bialystok et al. emphasized the following factors as more important in L2 learning than bilingualism per se: language of instruction, level of language proficiency, and the set of tasks used in examining L1 to L2 transfer. The influence of these factors, especially that of teaching methods, has also been pointed out by Seymour and Evans (1994) in learning English as a first language (L1) and by Liow and Poon (1998) in reading and spelling English as a second language (L2) in multilingual Singaporean Chinese children. Wang and Geva (2003) studied phonological and orthographic elements in spelling real English words and pseudo English words in 63 Grade 2 children - 30 Cantonese speaking and 33 native English speaking. They showed that the Chinese children learning English as L2 relied more on holistic, visual information rather than a phonological strategy to extract orthographic patterns in English spelling. Similar to Bialystok et al. (2003), Wang and Geva (2003) were careful to point out possible effects of socioeconomic status of the two groups and that the L1 Chinese children's limited English learning experience and their poorer vocabulary might further explain their difficulty in spelling English pseudowords.

The experimental studies with adults and children just outlined seem to suggest some specific rather than general influence of L1 on L2 English and of the possible use of visual-orthographic strategies by Chinese students to learn to read and spell English. We speculated that Chinese children in Hong Kong might also use more orthographic and lexical knowledge than phonological processing in reading and spelling English words for several reasons. One reason is the possible strong influence of the curriculum and approaches to teaching English. The primary English syllabus of the Hong Kong Education Department (1997) mandates that English should be taught as "communicating, inquiring, conceptualizing, reasoning and problem- solving" (p. 133). This key statement gives a good idea of the emphasis on meaning to the exclusion of teaching children to read and spell English as an alphabetic code. The other reason is that in a recent detailed study Shu, Chen, Anderson, Wu, and Xuan (2003) found that very little of the logic of Chinese characters is taught to Chinese children even though they may have some implicit awareness of the orthography to phonology and semantics relationship necessary for the encoding and decoding of characters or words. Moreover, Chinese children tend to learn to read and spell characters and words more by rote memory and practice in the form of drills than by an analysis-and-synthesis approach. The findings of Shu et al. suggest that these learning methods might likely influence the way Chinese children learn to read and spell English words. These lines of evidence-curriculum materials emphasizing form rather then function, teaching approaches focusing on meaning rather than the alphabetic code, and the lack of explicit teaching of the principle of the Chinese and the English orthographies-led us to explore the contribution of orthographic, word-specific knowledge and phonological processing to individual differences in reading and spelling English words by Chinese children. 


\section{ORTHOGRAPHIC, LEXICAL KNOWLEDGE, AND PHONOLOGICAL SENSITIVITY}

Orthographic or lexical knowledge and phonological sensitivity were the primary constructs employed in the present study. The orthographic form of a word is generally regarded as a sequence of letters relating in a systematic way to the phonological properties of the word (Ehri, 1980; Goswami, 1990). Orthographic knowledge is well explained by Barker, Torgesen, and Wagner (1992) as "[involving] memory for specific visual-spelling patterns that identify individual words, or word parts, on the printed page" (pp. 335-336). Orthographic and phonological processes might be separable but equal, and the latter process might be reinforced by the former, as argued by Foorman (1994, 1995). Alternatively, orthography and phonology are "integral" to one another even though it is difficult to devise "pure" measures of orthographic processing, just as it is difficult to devise "pure" measures of phonological processing (Wagner \& Barker, 1994). Typically, orthographic knowledge is assessed by such tasks as print exposure, orthographic choice (e.g., snoe-snow), homophonic choice of heterographic homophones (e.g., rose-rows for the name of a flower), and the like. Barker et al. (1992) showed that these latter two tasks made a significant contribution independent of level of phonological skill to five different types of reading measures, including timed and untimed isolated word recognition. Furthermore, variations of orthographic skills were found to be independent of the amount of reading experience.

Phonological sensitivity or awareness refers to the ability to conceptualize, reflect on, and manipulate sublexical segments of spoken language such as syllables with their onsets and rimes and phonemes. Typically, phonological sensitivity tasks require children to categorize and segment speech sounds. Categorization relates surface phonetic renderings to deep phonological categories of the language. This process involves the learning of allophonic variations and the linguistic contexts in which they occur. As an example, the English phonological category of the stop consonant $/ \mathrm{p} /$ contains the aspirated allophones [p] as in pate and the unaspirated [p] as in spate, varying according to the speech environment. Segmentation requires children to distinguish acoustic speech signals, which form a continuous stream because of the effect of coarticulation. More than one segment of information may be encoded in the same place of the speech signal, and similar acoustic properties may lead to the perception of more than one segment. Categorization and segmentation of speech sounds are both linguistic and cognitive activities and are likely constrained by the perceiver's sense of phonological and lexical structuring (Locke, 1983).

Within the twin framework of categorization and segmentation there is an array of tasks ranging from the cognitively and linguistically less demanding to the more complex, and from the "coarse-grained" (e.g., onsets and rimes) to the "fine-grained" (e.g., phoneme deletion and Spoonerism). The relative importance 
of onset-rime sensitivity and phoneme sensitivity and their causal role in early reading within a developmental framework is the subject of renewed, current debate (see Bryant, 2002; Goswami, 2002, Hulme et al., 2002; but see also Anthony \& Lonigan, 2004; Anthony et al., 2002). The developmental framework is important in that the efficacy of these phonological sensitivity tasks in predicting reading may change as reading skill develops. In a 5-year, longitudinal, multivariate correlational study involving 216 children, who were assessed annually from kindergarten through fourth grade, Wagner et al. (1997) showed that individual differences in a latent phonological awareness construct influenced subsequent individual differences in word-level reading for all the time periods examined, but serial naming and vocabulary receded with increasing stability of individual differences in word reading

\section{METHOD}

\section{Participants}

The 156 participants in this study were 10- to 12-year-old children in Grades 4, 5, and 6 in three "average" and fairly representative and comparable public and church elementary schools in Hong Kong. In these and in almost all other schools, English is taught from kindergarten onward, beginning with learning of the letters of the alphabet and progressing to word and sentence reading. But the teaching and learning are by and large of the traditional kind, with little training in the structure of the language. These upper elementary children were chosen based on our observation that they would have acquired some appreciation of orthographic and lexical knowledge and a very rudimentary understanding of speech sounds. The original sample size was over 300 children with about 100 for each grade. In an overall educational milieu of very heavy emphasis on weekly tests including mandatory written dictations, term and final examinations, and many other school activities, we and our team of trained research assistants had to work around these rigidly prescribed activities to accommodate the instructional needs of the schools and the demands of parents for more regular schoolwork. As a result, some children were unavoidably lost to the individual tasks administered after the completion of the group tasks even though nearly all the 300 or more children did all these group tasks given to whole classes or to small groups as appropriate.

This unexpected "wastage" beyond our control reduced the sample size to 156 children with full data on both group and individual tasks. For various reasons just outlined, participants for Schools A, B, and C were numbered respectively: 29, 24, and 103. Collapsing across schools, there were 44 children ( 17 boys and 27 girls) in Grade 4,76 children ( 40 boys and 36 girls) in Grade 5 , and 36 children ( 14 boys and 22 girls) in Grade 6. The mean ages in years for these three grades were, re- 
spectively, $9.88(S D=.43), 10.85(S D=.41)$, and $11.86(S D=.44)$. The mean age for the total group of 156 children was $10.81(S D=.83)$ years.

\section{Materials and Procedure}

A large battery of tasks presumed to assess orthographic and lexical knowledge and phonological sensitivity was devised. From initial tryouts and item analyses, six tasks with high discrimination values and median difficulty were selected on conceptual and methodological grounds to study individual differences in English word reading and spelling and to model English literacy acquisition in Chinese children. The Hong Kong adaptation of the Standard Raven's Progressive Matrices (Raven, Court, \& Raven, 1983), a decontextualized word reading task (both regular and exception words), and a written spelling task were also given to the children. The three orthographic and lexical knowledge tasks were all administered by paper and pencil to groups and took about $8 \mathrm{~min}$ each (about 25-30 min total). The three phonological sensitivity tasks were given individually and took about $30 \mathrm{~min}$ per child. The Progressive Matrices and the written spelling tasks were given to groups of children and took just over 20 min each. The individual isolated word reading task took about $8 \mathrm{~min}$ per child.

\section{Orthographic and Lexical Knowledge Tasks}

A set of tasks emphasizing orthographic and lexical knowledge, as it might be typically employed by students in the context of their curriculum, was devised. The tasks were not pure measures of orthography, as morphological, semantic, syntactic, and phonological factors were undoubtedly involved as well.

Past tense. The aim of this group task was to tap word-specific orthographic and lexical knowledge and to capitalize on the preponderant teaching of English grammatical structures in Hong Kong schools and the tendency of Chinese students to memorize the words in the curriculum. The task was an open-ended completion task with irregular verbs of the type: "Do not fall again; you (fell) yesterday." and "They sing beautifully now. Last week they (sang) poorly." Of the 20 items, 10 items (50\%) involved internal vowel change (e.g., drink - drank, hold - held); 3 items contained both internal vowel change plus a stem ending in a dental (tell - told, ride - rode, bite - bit); 2 items involved internal vowel change plus adding $\langle t\rangle$ or $/ t /$ (feel - felt); 2 items changed the final $\langle\mathrm{d}\rangle$ or $/ \mathrm{d} /$ to $\langle\mathrm{t}\rangle$ (build - built,send - sent); and 3 items involved no orthographical and phonological change (cut - cut, hit - hit, hurt - hurt). The priming verbs were shown in the short sentence frames in bold type on the printed sheet. The children were asked to read each sentence frame silently and carefully and to write down the correct past tense irregular verb derived from the base present 
tense. In the practice examples, the experimenters took great care to explain that the to-be-written irregular verbs would generally sound different from the present tense base forms but may share similar consonantal segments (e.g., see - saw, hear - heard). This careful explanation with examples should have minimized the possibility of the children simply writing down the regular -ed form for the to-be-spelled past verbs. Twenty of the original 24 items were found to be most discriminating, and the Cronbach's alpha coefficient for these items was .854 .

Orthographic choice. In this paper-and-pencil group task, the children were asked to underline the real word in a pair of lexical items consisting of one real English word and one homophonic pseudoword with similar word shape. Examples were soap, sope; gawn, gone; and shoe, shew. The original concept was from Olson, Kliegl, Davidson, and Foltz (1985). Barker et al. (1992) and Cunningham, Perry, Stanovich, and Share (2002) used similar items based on the same concept. These items were adapted from Manis, Seidenberg, Doi, McBride-Chang, and Petersen (1996) to suit the vocabulary level of the Hong Kong English learners. In agreement with Manis et al. (1996), this task cannot be considered to assess pure or unconfounded orthographic knowledge but the task does assess "something distinct from phonological decoding skills" (p. 170). Twenty item-pairs were selected from the original 36 pairs after item analysis, and the alpha coefficient was . 573 .

Orthographic-phonemic choice. In this paper-and-pencil group task, the children were asked to read silently each short simple or compound sentence embedding five orthographically and phonemically similar monosyllabic words or pseudowords and to underline the one correct word that completed the meaning of the sentence. Some sample items were "Do not give me just a part; give me the (hole whale whoal hoal whole) thing." "This is a (grate greet grait great greit) book." By using error substitutions, which were real words homophonous with the target word (e.g., "hole" for whole), compatible pseudohomophones (e.g., "hoal" for whole), and incompatible pseudohomophones (e.g., "whoal"), it was assumed the children would carry out the match-to-target task in a sentential context by orthographic and lexical comparison. Every effort was made to minimize confounds of orthographic with phonological knowledge sources and this was reasonably successful with the five choices in 13 of the 15 sentences. In the remaining 2 sentences a few of the foils drew on the lack of distinctness in the pronunciations of some words by many Chinese children (e.g., "shure", "share" uttered or read as homophonous with the target word shore). It was possible that some children might use both knowledge sources in completing this task. This task with five plausible choices embedded in a sentence context was a variant form and an improvement over the two-choice task (e.g., "What can you do with a needle and thread? "so, sew") used by Barker et al. (1992). Fifteen sentences with five real words or pseudowords embedded in each sentence frame formed the final task from the 
original 20 sentences with five lexical items each, and the alpha coefficient was .653 .

\section{Phonological Sensitivity Tasks}

Three tasks emphasizing phonological analysis, segmentation, and manipulation of phonemes were devised or adapted. Orthographic factors cannot completely be ruled out in these tasks, as children might utilize knowledge of word spellings as an aid in performing the tasks.

Pig Latin. In this task, the child listened to a spoken word with either one syllable or two syllables and was required to move the first segment (either initial consonant or consonant cluster according to the word) to the end of the word, add /ay/, and say the new word or pseudoword. The task was adapted from Nittrouer (1999, Appendix C). Examples were day (ayday), funny (unnyfay), that (atthay). All 24 items were found to be discriminating after item analysis, and the alpha value was .933 .

Phoneme deletion. In this task the child was asked to delete the initial, medial, or final phoneme of a heard pseudoword and to say the new word without the elicited speech sound. The task was adapted from Muter and Snowling (1997), who found it to be a powerful predictor of spelling skill in 9- to 10-year-old English children. From the original list of 24 items, 21 items were selected with 7 initial, 7 medial, and 7 final deletions administered in a randomized order (e.g., bice, mact, clart; bloot, fors $k$ ). The alpha coefficient for this task was .802 .

Spoonerism. The general idea of this task is the segmentation of heard words at the onset-rime level and the application of a novel phonological rule. Individual children were asked to listen to sets of two word-pairs or two item-pairs and to report them orally in such a way that their first sounds were exchanged or reversed. From the practice examples the children were carefully prepared to respond to onsets as consonants or consonant clusters. For example, gold-sheep would become shold-geep, sharp-chain should be uttered as charp-shain, and brain-thill as thain-brill. The original concept was from the work of Perin (1983) with 14-year-old dyslexic English children. Gillon and Dodd (1994) used a similar Spoonerism task in studying 8- to 10-year-old poor readers, and Leong (1999) in studying the spelling performance of fourth, fifth, and sixth graders. Following the task analysis of Landerl and Wimmer (2000), we awarded a score of 1 for a single correct response of speech segments in the interchange and a score of 2 for the correct interchange of both initial speech segments of clusters. After item analysis 12 item-pairs from the original 18 pairs were used for subsequent statistical treatment, and Cronbach's alpha was .905 . 


\section{Construct of Literacy}

Two indicators were used to subserve the latent dependent construct of literacy. One was a 42-item decontextualized individual English word reading task, and following Bradley and Bryant (1979) the same words embedded in short sentence frames were used as a group spelling task. There were 30 regular words such as beach, season, and $u g l y$ and 12 exception words such as island, busy, break, and lose. None of the exception words were of the "strange" kind such as aisle and yacht, as it has been shown by Walters, Bruck, and Malus-Abramowitz (1988) that these strange words were the hardest to spell. The 42 words that remained after item analysis came from an original 38-item list of regular words and a 35-item list of exception words based on curriculum materials used in Hong Kong elementary schools. The alpha coefficient for word reading was .935 and for spelling was .955 . The spelling task was given first as a group task, and after some 6 to 8 weeks the same task with the decontextualized words was administered as an individual word reading task.

The Standard Raven's Progressive Matrices (Raven et al., 1983) was used as a control for general learning ability in schools as the orthographic and lexical knowledge and phonological sensitivity tasks had a large element of learning (see Bryant, 2002, for argument).

\section{RESULTS}

Table 1 shows the means and standard deviations of the scores of the three orthographic and lexical knowledge tasks and the three phonological sensitivity tasks, word reading and spelling, Raven's Progressive Matrices, and chronological age for each grade and the total group of 156 children. Of the criterion tasks of word reading and spelling there was greater accuracy in reading than in spelling the same words, as expected. Table 2 shows the intercorrelations of the orthographic and lexical knowledge and phonological sensitivity tasks, reading and spelling, and chronological age for the total group. The coefficients range from moderate between phoneme deletion and word reading (.532) and spelling (.486) to high between past tense and reading (.784), past tense and spelling (.789), and word reading and spelling (.858). The correlations appear to group themselves roughly into sets of orthographic-lexical tasks and phonological tasks, with literacy measures correlating similarly with both groups of measures.

For the orthographic and lexical knowledge component a 3 (grade) $\times 3$ (orthographic and lexical knowledge task) multivariate analysis of variance (MANOVA) with Raven's and age as covariates was performed, followed by univariate analyses of variance (ANOVAs) for the tasks. Wilks's lambda of 6.011 was significant, suggesting overall difference among the three grades. The $F$ ratios were as follows: for the past tense task, $F(2,151)=18.540, p=.000$; for orthographic choice, $F(2,151)=$ $3.916, p=.022$; and for orthographic-phonemic choice, $F(2,151)=8.664 . p=.000$. 
TABLE 1

Means and Standard Deviations for Orthographic and Lexical Knowledge, Phonological Sensitivity Tasks, Word Reading, Spelling, Standard Raven's Progressive Matrices, and Chronological Age for Grade 4, 5, and 6 Children and the Total Group

\begin{tabular}{|c|c|c|c|c|c|c|c|c|}
\hline \multirow[b]{2}{*}{ Tasks } & \multicolumn{2}{|c|}{ Grade $4^{\mathrm{a}}$} & \multicolumn{2}{|c|}{ Grade $5^{b}$} & \multicolumn{2}{|c|}{ Grade $\sigma^{\mathrm{c}}$} & \multicolumn{2}{|c|}{ Total Group } \\
\hline & $M$ & $S D$ & $M$ & $S D$ & $M$ & $S D$ & $M$ & $S D$ \\
\hline Word reading ( $\max =42$ ) & 14.55 & 7.81 & 28.43 & 8.99 & 29.53 & 7.81 & 24.77 & 10.55 \\
\hline Spelling $(\max =42)$ & 7.91 & 7.04 & 21.57 & 8.80 & 23.61 & 6.74 & 18.19 & 10.19 \\
\hline Past tense $(\max =20)$ & 4.93 & 2.47 & 11.13 & 4.45 & 10.39 & 3.66 & 9.21 & 4.65 \\
\hline Orthographic choice $(\max =20)$ & 11.48 & 2.67 & 13.86 & 3.03 & 14.14 & 2.40 & 13.25 & 3.00 \\
\hline Orthographic-Phonemic choice $(\max =15)$ & 6.89 & 2.22 & 9.50 & 2.41 & 9.14 & 2.36 & 8.68 & 2.60 \\
\hline Pig Latin $(\max =24)$ & 6.55 & 7.09 & 12.54 & 8.39 & 12.50 & 8.64 & 10.84 & 8.49 \\
\hline Phoneme deletion $(\max =21)$ & 11.07 & 3.59 & 13.91 & 3.93 & 13.42 & 3.10 & 12.99 & 3.84 \\
\hline Spoonerism ( 12 item-pairs, $\max =24$ ) & 5.30 & 5.42 & 11.83 & 5.41 & 13.31 & 3.45 & 9.81 & 6.22 \\
\hline Raven's Progressive Matrices $(\max =60)$ & 43.07 & 4.88 & 45.38 & 5.92 & 47.83 & 4.55 & 45.29 & 5.58 \\
\hline Chronological age (years) & 9.88 & .43 & 10.85 & .41 & 11.86 & .44 & 10.81 & .83 \\
\hline
\end{tabular}

Note. $\max =\operatorname{maximum}$.

These $F$ ratios were all significant, but the difference was mainly between Grade 4 compared with Grades 5 and 6 and not between Grades 5 and 6 . For the phonological sensitivity component a 3 (grade) $\times 3$ (phonological sensitivity task) MANOVA was carried out with Raven's and age as covariates followed by univariate ANOVAs for the tasks. Wilks's lambda of 3.874 was significant at the .001 level. For Pig Latin, $F(2,151)=4.190, p=.017$; for phoneme deletion, $F(2,151)=4.577, p=.012$; and for Spoonerism, $F(2,151)=10.659, p=.000$. Similar to the multiple comparisons of grade performance in the orthographic and lexical knowledge construct. the differences were between Grades 4 and 5 and between 4 and 6 but not between Grades 5 and 6. From these results and because of the preponderant number of children from Grades 5 and $6(n=112)$ compared with the 44 children from Grade 4 , it was decided to use the total group of 156 children for the subsequent data analyses. This much larger number was also needed for the different structural equation analyses.

Preliminary stepwise multiple regression analyses were conducted to explore the contribution of the orthographic and lexical knowledge and phonological sensitivity tasks and age to word reading and spelling. For reading, $76.3 \%$ of the variance was accounted for by the conjoint contribution of past tense, Spoonerism, orthographic-phonemic choice, and orthographic choice, in that order. For spelling, $73.6 \%$ of the variation was explained by the conjoint contribution of past tense, orthographic choice, Spoonerism. and age, in that order. It should be noted that the past tense task, an indicator of the orthographic and lexical knowledge domain, alone accounted for most of the variation in both word reading $(61.5 \%)$ and spelling $(62.2 \%$; see the Discussion section). The strong contribution of the past tense 


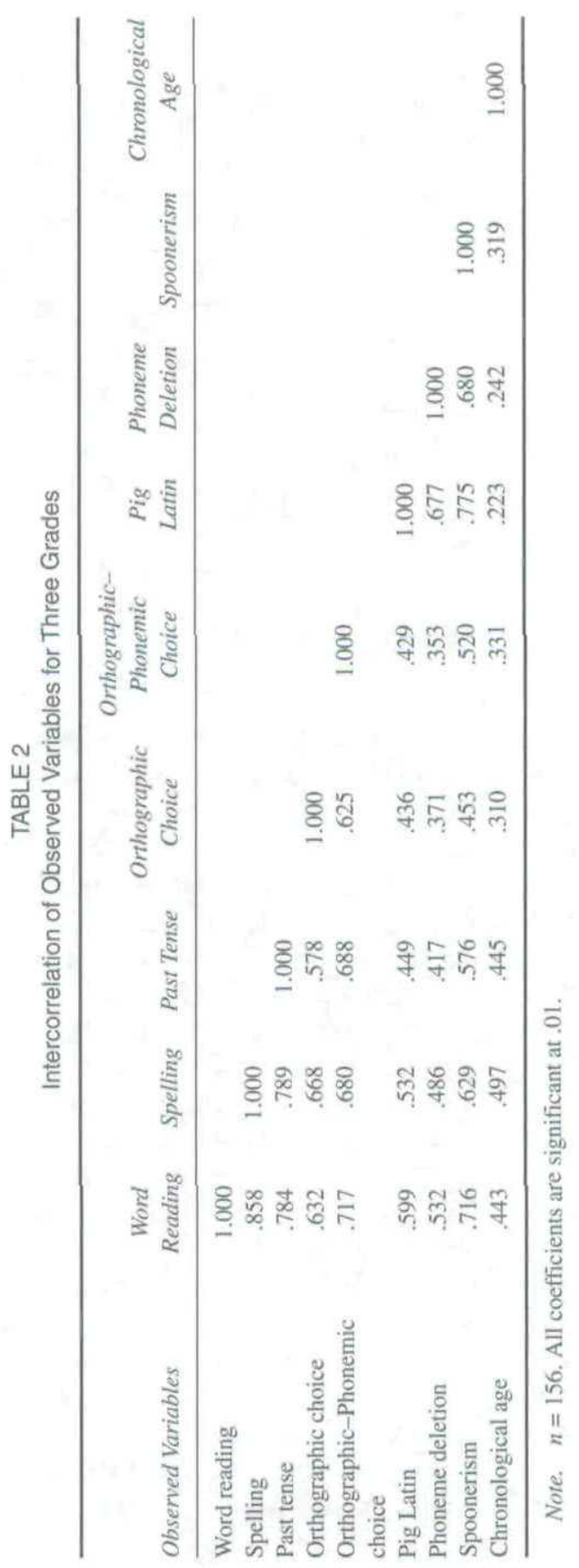


task was followed by Spoonerism (10.5\%) for word reading and orthographic choice $(6.8 \%)$ for spelling. The stepwise multiple regression analysis results are summarized in Table 3.

The next question examined the structural pattern of the three orthographic and lexical knowledge tasks and the three phonological sensitivity tasks and the extent of their clustering with word reading and spelling. Results of the varimax-rotated principal component analysis of these tasks are shown in Table 4. Two components emerged with fairly clear-cut patterns and accounted for $78.7 \%$ of the total variance. Component 1 consisted of all the orthographic and lexical knowledge tasks, both word reading and spelling, and accounted for $65 \%$ of the percentage total variance. Component 2 consisted of all the phonological sensitivity tasks and explained $13.72 \%$ of the total variation. This pattern further confirms the results of the stepwise multiple regression analyses and gives credence to the a priori postulate that orthographic and lexical knowledge and phonological sensitivity are separable though related.

In the structural equation model, orthographic and lexical knowledge and phonological sensitivity - each measured by three indicators - were hypothesized to predict children's literacy as measured by their reading and spelling performance (see Figure 1). The structural model was tested with the covariance matrix of the 156 children, using LISREL 8.53 (Jöreskog \& Sörbom, 1996-2001), following the strategies for small sample sizes in confirmatory factor analysis (Marsh \& Hau, 1999). Based on the various goodness-of-fit indexes as recommended by Marsh, Hau, and Grayson (in press) and the nonsignificant chi-square value, the model fit the data very well, $\chi^{2}(17, N=156)=26.16, p=.072$, with a root mean square error of approximation of .059 ( $p=.336$ for test of close fit), a nonnormed fit index of .990 , and a comparative fit index of .994 . These indexes thus support both the appropriateness of the indicators in measuring the latent constructs and the relationships among these latent constructs. Understandably, as in other structural equation or multivariate correlational analyses, the close fit of the model to the data merely indicates that the "model has survived a potential discreditation, but we cannot claim the model has been proven" (Hayduck, 1987, p. 159).

The results show that the respective factor loadings were substantially high, thus supporting the reliabilities and the appropriateness of using the various tasks in measuring the latent constructs. These loadings ranged from .72 to .86 for orthographic and lexical knowledge, from .75 to .92 for phonological sensitivity, and .91 to .94 for literacy. It should also be noted that orthographic and lexical knowledge and phonological sensitivity were substantially correlated at .86 .

The relative strengths of relations of orthographic and lexical knowledge and phonological sensitivity to literacy might be of central interest to this study. The results show a much stronger effect of the former than of the latter. Although orthographic and lexical knowledge had a very high prediction power (.83) on literacy, that of phonological sensitivity was substantially lower (.20). This structural equa- 


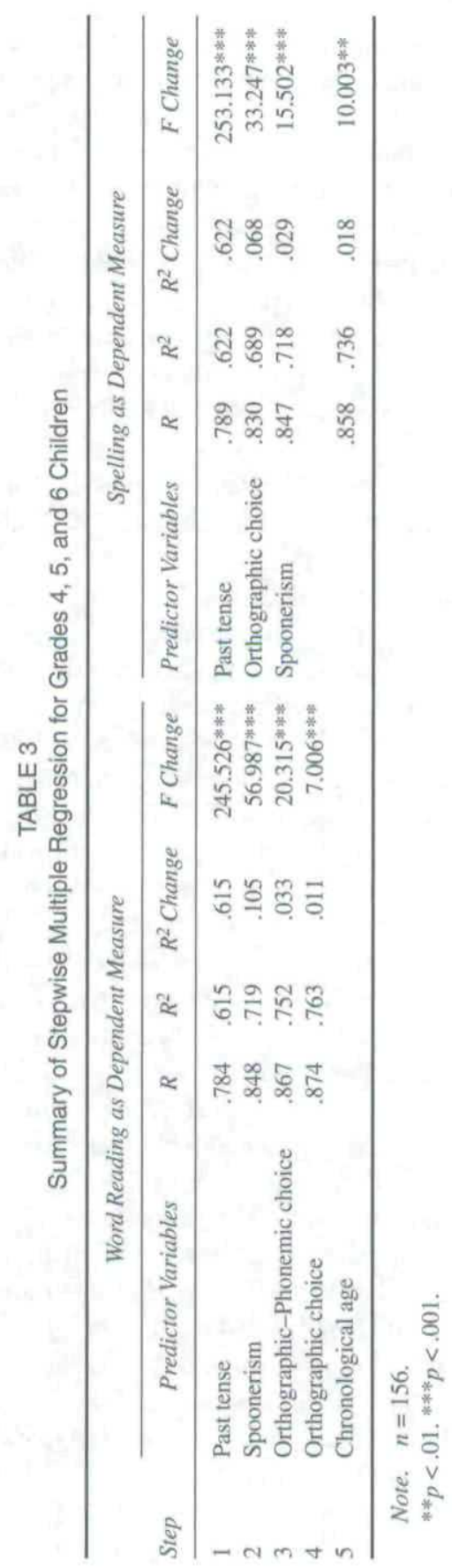


TABLE 4

Varimax-Rotated Principal Component Analysis of Orthographic and Lexical Knowledge, Phonological Sensitivity Tasks, Reading, and Spelling of Total Group

\begin{tabular}{lccc}
\hline & Component 1 & Component 2 & $h^{2}$ \\
\hline Past tense & 0.838 & 0.276 & 0.778 \\
Orthographic choice & 0.774 & 0.206 & 0.643 \\
Orthographic-Phonemic choice & 0.839 & 0.198 & 0.744 \\
Pig Latin & 0.280 & 0.863 & 0.823 \\
Phoneme deletion & 0.197 & 0.864 & 0.785 \\
Spoonerism & 0.420 & 0.810 & 0.832 \\
Word reading & 0.801 & 0.464 & 0.857 \\
Spelling & 0.837 & 0.369 & 0.836 \\
Eigenvalue & 5.20 & 1.098 & \\
\% total variance & 65.001 & 13.721 & $78.722^{\mathrm{a}}$ \\
\hline
\end{tabular}

Note. $n=156$.

aTotal \%.

\section{Standardized Solution}

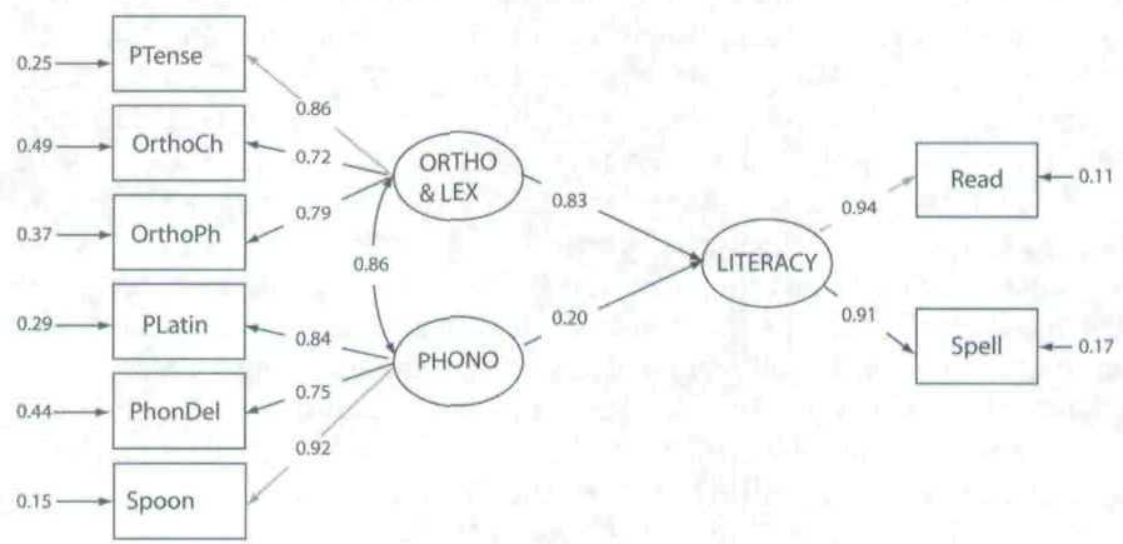

Chi-Square $=26.16, \quad \mathrm{df}=17, \quad p=0.072, \quad$ RMSEA $=0.059$

FIGURE 1 Structural equation modeling (LISREL 8.53) standardized solution of effect of latent independent constructs of orthographic and lexical knowledge (ORTHO \& LEX) and phonological sensitivity (PHONO) on the latent dependent construct of literacy (LITERACY). These tasks subserving orthographic and lexical knowledge: Past tense (PTense) (set to unity), orthographic choice (OrthoCh), and orthographic-phonemic choice (OrthoPh); these tasks subserving phonological sensitivity: Pig Latin (PLatin), phoneme deletion (PhonDel) and Spoonerism (Spoon) (set to unity); and word reading (Read) (set to unity) and spelling (Spell) subserving LITERACY. 
tion analysis provides a powerful procedure in estimating the structure and interrelationships of the various latent domains, and the measure of the relationships between observed variables and unobserved components, when these relationships are defined a priori.

\section{DISCUSSION}

In this study we examined the component processes of English word reading and spelling in 156 10- to 12-year-old Chinese children in Hong Kong, where beginning English reading is taught through the concept-driven, meaning emphasis and not so much the data-driven, code emphasis. Taking into account research findings and cultural and educational milieu, we hypothesized there would be considerably more contribution to individual differences from the orthographic and lexical knowledge construct than the phonological sensitivity domain. Our results merit attention in several ways.

First, our finding of a greater effect of orthographic and lexical knowledge than phonological sensitivity on English word reading and spelling obtained from multiple regression analyses, principal component analysis, and structural equation modeling support and add to current studies of reading-related skills in children from different linguistic backgrounds, including Chinese learning English as L2 (Cheung, Chen, Lai, Wong, \& Hills, 2001; Chiappe, Siegel, \& Gottardo, 2002; Chiappe, Siegel, \& Wade-Woolley, 2002; Gottardo, Yan, Siegel, \& Wade-Woolley, 2001; Ho \& Bryant, 1997; McBride-Chang \& Kail, 2002). All these studies point to the role of phonological awareness in acquiring alphabetic literacy. Our results with older elementary school-age Chinese learners of English as L2 go beyond these findings. Our results show that 156 Chinese children with a modal age of 10.8 years relied more on orthographic and lexical knowledge than phonological sensitivity to read and spell regular and exception English words. These results support the recent findings with Chinese children by Bialystok et al. (2003) and particularly with Cantonese-speaking Chinese children by Wang and Geva (2003), as reviewed earlier. What might be the reasons for this pattern of structural relation of this word-specific knowledge to the construct of literacy?

One plausible explanation for our findings was the possible effect from entrenched teaching for meaning, rather than for the analysis and synthesis of grapheme-phoneme and phoneme-grapheme correspondences, on Chinese children learning to read and spell English words. In making this statement we also draw on some current findings of the possible cross-over effect from the practice of repetitions and drills in learning Chinese characters and words as suggested by Shu et al. (2003). The massive amount of practice in using lexical, semantic, and sublexical procedures in deriving phonology from Chinese orthography in reading aloud and from sound to print in spelling likely affects the brain regions involved in 
reading and spelling, as discussed by Fiez (2000). The implication is that native language learning affects reading strategies. There is some evidence in this regard from a recent neuroimaging study by Tan et al. (2003). In their functional magnetic resonance imaging (fMRI) study to visualize the brain activities of Chinese-English bilinguals in processing logographic Chinese and alphabetic English, Tan et al. found their bilingual Chinese participants applied their L1 learning strategy to their L2 English reading. This implies that their participants were less able to use grapheme-to-phoneme rules to read English words. These neuroimaging results further support the findings of greater involvement of orthographic than phonological information in adult Chinese learners reading English words as shown by Wang, Koda, and Perfetti (2003) and in the English spelling performance of Chinese children using English as a second language as found by Wang and Geva (2003). If these fMRI results are further confirmed, they might provide a possible neurocognitive explanation for our finding of the greater involvement of orthographic and lexical knowledge as shown in the multiple regression analyses (Table 3 ), the principal component analysis (Table 4), and the structural equation analysis summarized in the path diagram (Figure 1).

Our finding of the very substantial contribution of some $62 \%$ from the word-specific English past tense task to both reading and spelling words indicates the fairly pervasive role of orthographic and lexical knowledge. The correct usage of irregular past tense in English depends on knowledge of both related orthographic and phonological segments and semantic-syntactic contexts. To write the correct irregular past tense the child must ascertain that verbs such as break-broke, draw-drew, and hold-held have the same meaning; that one is in the present tense and the other the past tense; and that the past tenses are respectively broke, drew, and held and not the regularized but unacceptable forms of *broked, *drawed, or *holded. There are shared orthographic and phonological features of the base and past forms. In keeping with general findings in linguistics, 10 items of the 20 items of this task involve internal vowel change as shown in the previous examples. The consonantal structure provides the cue, and it is in this sense this task is hypothesized to assess orthographic and lexical knowledge. All the aforementioned three items offer both the same initial and final consonants or consonant clusters.

Production of vowel change in irregular past tense forms is more a matter of lexical selection and not so much rule application. If it is the latter, then nonwords will be produced. It is likely that orthographic and phonological knowledge and semantic-syntactic context all play a role in lexical selection in this task. In this task the "priming" verbs and the to-be-written target irregular verbs were all selected to be at about the Grade 4 or 5 level and the sentential contexts embedding the verbs were all simple, active, and declarative sentences, thus minimizing the semantic and syntactic load.

A similar explanation of lexical selection from the repertoire of words known to the children is also evident from a careful study of all the answers by the 156 chil- 
dren to all the items of the orthographic-phonemic choice task. The children seemed to focus almost entirely on the real words homophonous with the target words and the target words themselves, which were all in their reading vocabulary, and ignored pseudohomophones and nonsense words with similar though not identical phonology to the target.

After the considerable effect of past tense as just explained, the next major contribution to word reading was from Spoonerism $(10.5 \%)$ and to spelling was from orthographic choice (6.8\%). This differential pattern was of interest in that Spoonerism taps sensitivity to novel phonological rules and may apply more to reading. A careful task analysis shows that this task requires the segmentation of heard words at the onset-rime level and not so much at the individual phonemic level. The manipulation of the larger onset-rime units than the smaller phonemic segments is relatively easier for Chinese learners of English (see McBride-Chang \& Kail, 2002). The task is linguistically and cognitive fairly complex in that the children must hold the speech segments in working memory, blend the interchanged consonants or consonant clusters, and say two novel words or pseudowords.

Orthographic choice, which draws on orthographic comparisons of heterographic homophonic words (accounting for an additional $6.8 \%$ of variation), followed the contribution of $62 \%$ (Table 3 ) to written spelling by the orthographic and lexical knowledge task of past tense. These results are in line with current findings that beginning readers are able to utilize word-specific knowledge in an analogical manner to aid reading and spelling of printed words (Ehri, 1997; Ehri \& Wilce, 1980; Goswami, 1986).

Strong support for the assertion of the structural relation of orthographic and lexical knowledge and phonological sensitivity to word reading and spelling comes from the structural equation analysis. The good fit of the model to the data, the high loadings of the individual tasks to the latent constructs, and the much stronger impact of orthographic and lexical knowledge than phonological sensitivity on literacy substantiate the claim of the importance of orthographic and lexical knowledge, at least for this sample of Chinese children learning to read and spell English.

One limitation of this study is that the reasons for a preponderance of lexical and orthographic, as opposed to phonological contributions to literacy, are not clear. It is possible that these are transfer effects from the nonanalytic, rote-learning style employed in learning Chinese. Alternatively, as noted earlier, the importance of lexical-orthographic variables in reading and spelling may derive from the strong meaning-based English literacy curriculum. Without an appropriate comparison group with a different L1, a different L1 curriculum, or a different L2 curriculum, the source of the lexical-orthographic contribution cannot be pinpointed in this study. Despite the good fit of the model to these data, other constructs should also be examined in future studies. For example, phonological working memory and phonological naming components (Wagner et al., 1997) and a component explicating automaticity in processing linguistic data and alphanu- 
merics (e.g., van den Bos, Zijlstra, \& van den Broeck, 2003). Individual differences in L1 and L2 reading acquisition can be partially explained by these substrates (Geva \& Wang, 2001).

In conclusion, from our structural equation analyses we demonstrated a set of parsimonious estimates that related domains of orthographic and lexical knowledge and phonological sensitivity to literacy. We did not "prove" the composition of the correct model. On the contrary, we simply showed our "model has survived a challenge" (Hayduck, 1987, p. 163).

\section{ACKNOWLEDGMENTS}

This study was supported by Grant SSHRC 410-01-0059 from the Social Sciences and Humanities Research Council of Canada awarded to Che Kan Leong, a research grant from the University Grants Committee to Li Hai Tan, and internal university research grants to Pui Wan Cheng and Kit Tai Hau. We are grateful for the assistance.

We thank the teachers and the children and their parents in the three schools in Hong Kong for their cooperation, and we thank our research assistants for their group and individual testing in the schools over an extended period. The insightful comments and suggestions from the editor, Dr. Frank Manis, and the three anonymous reviewers have greatly helped us in our considerable revision and are gratefully acknowledged. None of these colleagues are responsible for any shortcomings, which are necessarily our own.

\section{REFERENCES}

Adams, M. J. (1990), Beginning to read: Thinking and learning about print. Cambridge, MA: MIT Press.

Anthony, J. L., \& Lonigan, C. J. (2004). The nature of phonological awareness: Converging evidence from four studies of preschool and early-grade school children, Journal of Educational Psychology, $96,43-55$.

Anthony, J. L., Lonigan, C. J., Burgess, S. R., Driscoll, K., Phillips, B. M., \& Cantor, B. G. (2002). Structure of preschool phonological sensitivity: Overlapping sensitivity to rhyme, words, syllables, and phonemes. Journal of Experimental Child Psychology, 82, 65-92.

Barker, T. A., Torgesen, J. K., \& Wagner, R. K. (1992). The role of orthographic processing skills on five different reading tasks. Reading Research Quarterly; 27, 334-345.

Bialystok, E., Majumder, S., \& Martin, M. M. (2003). Developing phonological awareness: Is there a bilingual advantage? Applied Psycholinguistics, 24, 27-44.

Bradley, L., \& Bryant, P. (1979). The independence of reading and spelling in backward and normal readers. Developmental Medicine and Child Neurology, 21, 504-514.

Bryant, P. (2002). It doesn't matter whether onset and rime predicts reading better than phoneme awareness does or vice versa. Journal of Experimental Child Psychology, 82, 41-46. 
Byme, B. (1996). The learnability of the alphabetic principle: Children's initial hypotheses about how print represents spoken language. Applied Psycholinguistics, 17, 401-426.

Cassar, M., \& Treiman, R. (1997). The beginnings of orthographic knowledge: Children's knowledge of double letters in words. Journal of Educational Psychology, 89, 631-644.

Cheung, H., Chen, H.-C., Lai, C. Y., Wong, O. C., \& Hill, M. (2001). The development of phonological awareness: Effects of spoken language experience and orthography. Cognition, 8, 227-241.

Chiappe, P., Siegel, L. S., \& Gottardo, A. (2002). Reading-related skills of kindergartners from diverse linguistic backgrounds. Applied Psycholinguistics, 23, 95-116.

Chiappe, P., Siegel, L. S., \& Wade-Woolley, L. (2002). Linguistic diversity and the development of reading skills: A longitudinal study. Scientific Studies of Reading, 6, 369-400.

Cunningham, A. E., Perry, K. E., Stanovich, K. E., \& Share, D. L. (2002). Orthographic learning during reading: Examining the role of self-teaching. Journal of Experimental Child Psychology, 82, 185-199.

Ehri, L. C. (1980). The development of orthographic images. In U. Frith (Ed.), Cognitive processes in spelling (pp. 311-338). London: Academic.

Ehri, L. C. (1997). Learning to read and learning to spell are one and the same, almost. In C. A. Perfetti, L. Rieben, \& M. Fayol (Eds.), Learning to spell: Research, theory, and practice across languages (pp. 237-269). Mahwah, NJ: Lawrence Erlbaum Associates, Inc.

Ehri, L. C., \& Wilce, L. (1980). The influence of orthography on readers' conceptualization of the phonemic structure of words. Applied Psycholinguistics, 1,371-385.

Fiez, J. A. (2000). Sound and meaning: How native language affects reading strategies. Nature Neuroscience, 3, 3-5.

Foorman, B. R. (1994). Phonological and orthographic processing: Separate but equal? In V. W. Berninger (Ed.), The varieties of orthographic knowledge. I: Theoretical and developmental issues (pp. 321-357). Dordrecht, The Netherlands: Kluwer Academic.

Foorman, B. R. (1995). Practical connections of orthographic and phonological processing. In V.W. Berninger (Ed.), The varieties of orthographic knowledge. II: Relationships to phonology, reading, and writing (pp. 377-419). Dordrecht, The Netherlands: Kluwer Academic.

Geva, E., \& Wang, M. (2001). The development of basic reading skills in children: A cross- language perspective, Annual Review of Applied Linguistics, 21, 182-204.

Gillon, G., \& Dodd, B. J. (1994). A prospective study of the relationship between phonological, semantic and syntactic skills and specific reading disability. Reading and Writing: An Interdisciplinary Journal, 6, 321-345.

Goswami, U. (1986). Children's use of analogy in learning to read: A developmental study. Journal of Experimental Child Psychology, 42, 73-83.

Goswami, U. (1990). Phonological priming and orthographic analogies in reading. Journal of Experimental Child Psychology, 49, 323-340.

Goswami, U. (2002). In the beginning was the rhyme? A reflection on Hulme, Hatcher, Nation, Brown, Adams, and Stuart (2002). Journal of Experimental Child Psychology, 82, 47-57.

Goswami, U., \& Bryant, P. E. (1990). Phonological skills and learning to read. Hillsdale, NJ: Lawrence Erlbaum Associates, Inc.

Gottardo, A., Yan, B., Siegel, L. S., \& Wade-Woolley, L. (2001). Factors related to English reading performance in children with Chinese as a first language: More evidence of cross- language transfer of phonological processing. Journal of Educational Psychology, 93, 530-542.

Hayduck, L. A. (1987). Structural equation modeling with LISREL: Essentials and advances. Baltimore: Johns Hopkins University Press.

Ho, C. S.-H., \& Bryant, P. (1997). Development of phonological awareness of Chinese children in Hong Kong. Journal of Psycholinguistic Research, 26, 109-126.

Hong Kong Education Department. (1997). Syllabuses for primary schools: English language primary 1-6. Hong Kong: Hong Kong Government. 
Hulme, C., Hatcher, P. J., Nation, K., Brown, A., Adams, J., \& Stuart, G. (2002). Phoneme awareness is a better predictor of early reading skills than onset-rime awareness. Journal of Experimental Child Psychology, 82, 2-28.

Jöreskog, K. G., \& Sörbom, D. (1996-2001). LISREL 8: User's reference guide. Lincolnwood, IL: SSI Scientific Software International.

Koda, K. (2000). Cross-linguistic variations in L2 morphological awareness. Applied Psycholinguistics, 21, 297-320.

Landerl, K., \& Wimmer, H. (2000). Deficits in phoneme segmentation are not the core problem of dyslexia: Evidence from German and English children. Applied Psycholinguistics, 21, 243-262.

Leong, C. K. (1999). Phonological coding and children's spelling. Annals of Dyslexia, 49, 195-220.

Lesaux, N. K., \& Siegel, L. S. (2003). The development of reading in children who speak English as a second language. Developmental Psychology, 39, 1005-1019.

Liow, S. J. R., \& Poon, K. K. L. (1998). Phonological awareness in multilingual Chinese children. Applied Psycholinguistics, 19, 339-362.

Locke, J. (1983). Phonological acquisition and change. New York: Academic.

Manis, F. R., Seidenberg, M. S., Doi, L. M., McBride-Chang, C., \& Petersen, A. (1996). On the bases of two subtypes of developmental dyslexia. Cognition, 58, 157-195.

Marsh, H. W., \& Hau, K. T. (1999). Confirmatory factor analysis: Strategies for small sample sizes. In R. H. Hoyle (Ed.), Statistical strategies for small sample research (pp. 251-284). London: Sage.

Marsh, H. W., Hau, K. T., \& Grayson, D. (in press). Goodness of fit evaluation in structural equation modeling. In A. Maydeu-Olivares \& J. McCardle (Eds.), Psychometrics. A Festschrift to Roderick P. McDonald. Mahwah, NJ: Lawrence Erlbaum Associates, Inc.

McBride-Chang, C., \& Kail, R. V. (2002). Cross-cultural similarities in the predictors of reading acquisition. Child Development, 73, 1392-1407.

Muljani, D., Koda, K., \& Moates, D. R. (1998). The development of word recognition in a second language. Applied Psycholinguistics, 19, 99-113.

Muter, V., \& Snowling, M. (1997). Grammar and phonology predict spelling in middle childhood. Reading and Writing: An Interdisciplinary Journal, 9, 407-425.

Nittrouer, S. (1999). Do temporal processing deficits cause phonological processing problems? Journal of Speech, Language, and Hearing Research, 42, 925-942.

Olson, R., Kliegl, R., Davidson, B., \& Foltz, G. (1985). Individual and developmental differences in reading disability. In T. Waller (Ed.), Reading research: Advances in theory and practice (Vol. 4, pp. 1-64). London: Academic Press.

Perin, D. (1983). Phonemic segmentation and spelling. British Journal of Psychology, 74, 129-144.

Raven, J. C., Court, J. H., \& Raven, C. (1983). Manual for Raven's Progressive Matrices and Vocabulary Scales, part three, section 7, research. London: H. K. Lewis.

Seymour, P. H .K., \& Evans, H. M. (1994). Levels of phonological awareness and learning to read. Reading and Writing: An Interdisciplinary Journal, 6, 221-250.

Shu, H., Chen, X., Anderson, R. C., Wu, N., \& Xuan, Y. (2003). Properties of school Chinese: Implications for learning to read. Child Development, 74, 27-47.

Tan, L. H., Spinks, J. A., Feng, C.-M., Siok, W. T., Perfetti, C. A., Xiong, J., et al. (2003). Neural systems of second language reading are shaped by native language. Human Brain Mapping, 18, 159-166.

Treiman, R. (1993). Beginning to spell: A study of first-grade children. New York: Oxford University Press.

Treiman, R., \& Cassar, M. (1997). Effects of morphology on children's spelling of final consonant clusters. Journal of Experimental Child Psychology, 63, 141-170.

Van den Bos, K. P., Zijlstra, J. H., \& van den Broeck, W. (2003). Specific relations between alphanumeric-naming speed and reading speeds of monosyllabic and multisyllabic words. Applied Psycholinguistics, 24, 407-430. 
Wagner, R. K., \& Barker, T. A. (1994). The development of orthographic processing ability. In V. W. Berninger (Ed.), The varieties of orthographic knowledge. I: Theoretical developmental issues (pp. 243-276). Dordrecht. The Netherlands: Kluwer Academic.

Wagner, R. K., \& Torgesen, J. K. (1987). The nature of phonological processing and its causal role in the acquisition of reading skills. Psychological Bulletin. 101, 192-212.

Wagner, R. K., Torgesen, J. K., Rashotte, C. A., Hecht, S. A., Barker, T. A., Burgess, S. R., et al. (1997). Changing relations between phonological processing abilities and word-level reading as children develop from beginning to skilled readers: A 5-year longitudinal study. Developmental Psychology, 33, 468-479.

Walters, G., Bruck, M., \& Malus-Abramowitz, M. (1988). The role of linguistic and visual information in spelling: A developmental study. Journal of Experimental Child Psychology, 45, 400-421.

Wang, M., \& Geva, E. (2003). Spelling performance of Chinese children using English as a second language: Lexical and visual-orthographic processes. Applied Psycholinguistics, 24, 1-25.

Wang, M., Koda, K., \& Perfetti, C. A. (2003). Alphabetic and nonalphabetic L1 effects in English word identification: A comparison of Korean and Chinese English L2 learners. Cognition, 87, 129-149.

Manuscript received January 27, 2003

Accepted April 2, 2004 
Copyright of Scientific Studies of Reading is the property of Lawrence Erlbaum Associates and its content may not be copied or emailed to multiple sites or posted to a listserv without the copyright holder's express written permission. However, users may print, download, or email articles for individual use. 